the period of unconsciousness was due to hypoglycaemia the history and rapid response to buccal glucose allows a confidant clinical diagnosis to be made. According to Libby et al there are many possible ways in which hypoglycaemia could be deleterious to the myocardium. Severely ischaemic myocardium is dependent on anaerobic pathways for its energy production and is thus uniquely dependent on carbohydrate substrates. In addition, hypoglycaemia is known to produce a sympathoadrenal discharge which could increase heart rate, ventricular afterload, and the inotropic state of the myocardium, with a resulting increase in myocardial oxygen consumption.

In spite of the paucity of recorded cases, there seems to be evidence that a hypoglycae- mic episode presents a period of risk for myocardial infarction, particularly in patients with underlying ischaemic heart disease. A routine ECG in such circumstances may reveal more cases.

1 Libby P, Maroko PR, Braunwald E. The effect of hypoglycaemia on myocardial ischaemic injury during acute experimental coronary artery occlusion. Circulation 1975;51:621-6.

2 Arora RR, Meisheri YV, Joshi V. Myocardial infarction secondary to hypoglycaemia. Case reports. Indian Heart $\mathcal{F}$ 1980;32:186-9.

3 Wray R, Sutcliffe SB. Propranolol-induced hypoglycaemia and myocardial infarction. BMF 1972;ii:592.

4 Markel A, Keidar S, Yasin K. Hypoglycaemia-induced ischaemic ECG changes. Presse Med 1994;23:78-9.

5 Pauli P, Hartl L, Marquardt C, Stalmann H, Strian F. Heartbeat and arrhythmia perception in diabetic autoHeartbeat and arrhythmia perception in diabe

6 Oganov RG, Aleksandrov AA, Vinogradova IV. Sensitivity to insulin in acute myocardial infarction. Kardiologiia 1977; 17:89-94.

\title{
Inadvertent subclavian artery puncture in an intravenous drug abuser
}

\author{
Gordon W McNaughton, Ian J Swann
}

\begin{abstract}
Arterial complications from inadvertent arterial puncture in intravenous drug abusers are well recognised. Most reports describe injury to the femoral artery with occasional reports of brachial and radial artery injury. A case of subclavian artery injury is described in this paper, and the pathophysiology and treatment of intraarterial drug injection discussed.

(F Accid Emerg Med 1996;13:358-359)
\end{abstract}

Key terms: subclavian artery injury; intravenous drug abuse

\section{Case report}

A 25 year old male intravenous drug abuser presented to the accident and emergency (A\&E) department 30 minutes after injecting heroin into his right supraclavicular fossa. He experienced transient pain and paraesthesiae from the injection site down to his hand. This was followed by severe pain and erythema in a well demarcated area over the right side of his neck and supraclavicular fossa. The skin was warm, erythematous, and hypersensitive. Distal pulses were normal but a bruit was audible in both the supraclavicular fossa and in the axilla. The patient was admitted to hospital for observation. His symptoms and signs resolved over a three hour period and he was discharged later that day. He reattended the A\&E department 10 days later with a heroin overdose. Further assessment at that stage confirmed complete resolution without residual bruit.

\section{Discussion}

Glasgow is comparable to many other inner city areas in that it has a large population of

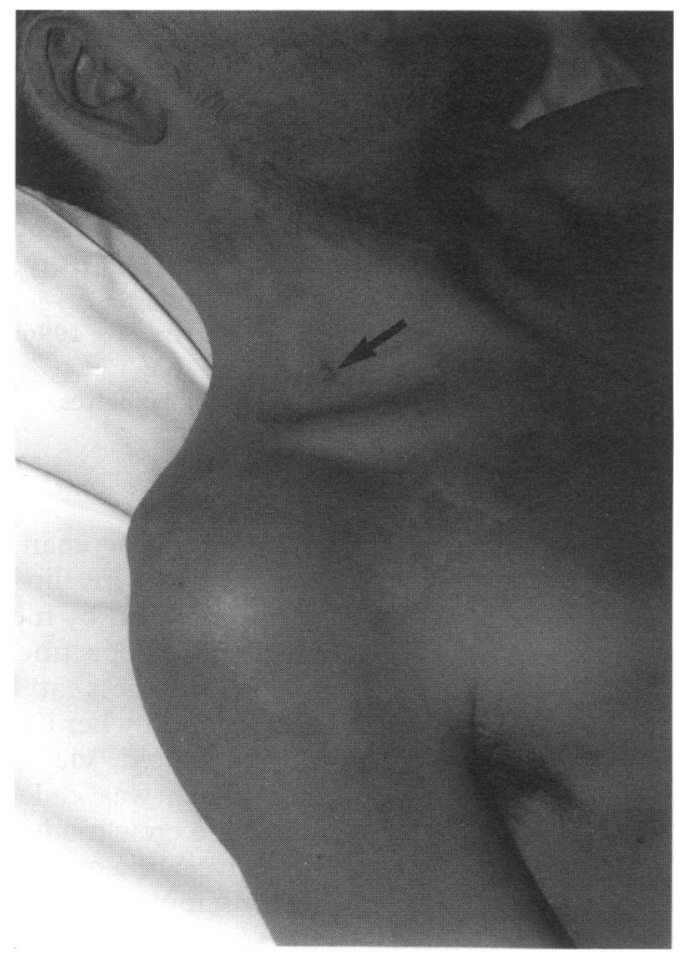

Photograph showing area of central ischaemia with surrounding reactive hyperaemia. Note the injection site in supraclavicular fossa.

chronic intravenous drug abusers, with estimates of approximately 9500 regular users. ${ }^{1}$ Many have been injecting for years and due to the sclerosing effect of the injection have little peripheral venous access. Most, however, have some knowledge of the anatomy of the central veins. When peripheral access is not obtainable, the femoral vein is the route favoured by 
most. Neck veins are rarely used, probably due to a combination of difficulty with access and fear of carotid artery puncture. Given the large numbers of intravenous drug abusers, it is not surprising that complications associated with accidental intra-arterial injection sometimes occur. However, a search yielded only two reports of injury to the subclavian artery (both false aneurysms). ${ }^{23}$

The well demarcated territory outlined in the figure suggests that the site of injection was the thyrocervical trunk. This is the largest branch arising from the first part of the subclavian artery and supplies the shoulder girdle, and parts of the neck and thyroid. ${ }^{4}$

The pathophysiology of ischaemia from intra-arterial injection is complex. Small vessel embolisation, chemical endarteritis, toxic effect on the endothelium, and vasospasm have all been implicated. ${ }^{56}$ There remains considerable debate about the exact role played by vasospasm. Initial work on an animal model showed no evidence of vasospasm with drugs of abuse. ${ }^{7}$ However, reduced blood flow was noted when substances frequently "cut" with drugs (for example, corn starch and talcum) were injected into arteries. More recently a paper examining the effect of vasodilator drugs on intra-arterial injection related limb ischaemia concluded that the success of these drugs was related in part to the presence of vasospasm. $^{6}$

It is recommended that all patients sustaining intra-arterial injection should be admitted for observation. ${ }^{7}$ The need for further treatment is based on the presence or absence of distal pulses. Where there is evidence of large vessel involvement, angiography is indicated. Various treatments have been used successfully to maintain limb circulation including surgery, heparin, thrombolysis, vasodilator drugs, and prostacyclin infusions. ${ }^{6-11}$ There have been no randomised trials to determine the optimum treatment.

In the patient described here there was no evidence of distal large vessel involvement. The signs visible at the time of presentation represent reactive hyperaemia secondary to initial ischaemia; these changes have previously been described in the upper limb and are known as a "hand trip". ${ }^{12}$ This patient's signs and symptoms rapidly resolved with conservative treatment. Heroin is water soluble, which partly explains why there was little damage to the microcirculation. This is in contrast to temazepam, another drug used by intravenous drug abusers in Glasgow, which solidifies in the microcirculation, often with catastrophic effects. ${ }^{13}$ The presence of an arterial bruit at the time of first presentation which spontaneously resolved remains unexplained, but may have been due to intimal damage or local haematoma.

This case report outlines a rare presentation of a complication of parenteral drug misuse. Given an aging population of intravenous drug abusers who have increasing difficulty finding venous access, doctors working in $\mathrm{A} \& \mathrm{E}$ departments will undoubtedly see similar complications in the future. They should be aware of the potentially serious nature of intra-arterial injection and should refer these patients to vascular surgeons at an early stage. Finally, the reattendance of the same patient 10 days later, this time with a heroin overdose, suggests that serious complications may be no deterrent to continued substance abuse.

1 Frischer $M$. Estimated prevalence of injecting drug use in Glasgow. Br $\mathcal{F}$ Addict 1992;87:235-43.

2 Ortega JL, Neira F, Ruiz C, Madrazo A, Rivas G, Sanchez $\mathrm{G}$, et al. Intraoperative rupture of subclavian aneurysm caused by self intra-arterial injections in a drug addict [Letter]. Rev Esp Anestesiol Reanim 1995;42:156.

3 O'Leary MR. Subclavian artery false aneurysm associated with branchial plexus palsy: a complication of parenteral with branchial plexus palsy: a complication of par
drug addiction. Am $\mathcal{F}$ Emerg Med 1990;8:129-33.

4 Romanes GJ. Cunningham's manual of practical anatomy, 15th ed, vol 3. Oxford: Oxford University Press, 1986.

5 Dodd TJ, Scott RN, Woodburn KR, Going JJ. Limb ischaemia after intraarterial injection of temazepam gel: histology mia after intraarterial injection of temazepa

6 Silverman SH, Turner WW. Intra-arterial drug abuse; new Silverman SH, Turner WW. Intra-arterial drug

7 Wright CB, Lamoy RE, Hobson RW. Hemodynamic effects of intra arterial injection of drugs of abuse. Surgery 1976; 79:425-31.

8 Stonebridge PA, Callam MJ, Farouk M, Murie JA. Intra-arterial injection of oral medication in HIV positive drug addicts. $B r \mathcal{F}$ Surg 1990;77:333-4.

9 Yeager RA, Hobson RW, Padberg FT, Lynch TG, Chakravarty $M$. Vascular complications related to drug abuse. J Trauma 1987;27:305-8.

10 Treiman GS, Yellin AE, Weaver FA, Barlow WE, Treiman RL, Gaspar MR. An effective treatment protocol for intraarterial injection. $₹$ Vasc Surg 1990;12:456-65.

11 Samuel I, Bishop CC, Jamieson CW. Accidental intra arterial drug injection successfully treated with Iloprost. Eur $\mathcal{f}$ rial drug injection success

12 Maxwell TM, Olcott C, Blaisdell FW. Vascular complications of drug abuse. Arch Surg 1972;105:875-81.

13 Scott RS, Woodburn KR, Reid DB, Maraj B, Going J, Gilmour DG, et al. Intra-arterial temazepam [Letter]. BMF 1994;304:1630.

\section{Ecstasy induced retropharyngeal emphysema}

Homerton Hospital, London E9

M Onwudike

Correspondence to: Madu Onwudike FRCSEd, 1 Thornwood Close, South Woodford, London E18 $1 \mathrm{RH}$, United Kingdom.

\author{
Madu Onwudike
}

\author{
Abstract \\ This is the first reported case of isolated \\ retropharyngeal emphysema caused by \\ ingestion of the amphetamine derivatives \\ "Ecstasy" and "Speed". The same com- \\ plication has been reported with mari- \\ huana, cocaine, and heroin abuse. The
}

condition resolved spontaneously and this seems to be the experience of others who have reported cases of cervical emphysema and pneumomediastinum associated with substance abuse. Because of the self limiting nature of this condition, extensive investigations may not be neces- 